\title{
Characterization of a silica-PVA hybrid for high density and stable silver dissolution
}

DOI:

10.1016/j.matchemphys.2016.03.022

\section{Document Version}

Accepted author manuscript

Link to publication record in Manchester Research Explorer

\section{Citation for published version (APA):}

Dorin, B., Zhu, G., Parkinson, P., Perrie, W., Benyezzar, M., \& Scully, P. (2016). Characterization of a silica-PVA hybrid for high density and stable silver dissolution. Materials Chemistry and Physics, 177, 19-24.

https://doi.org/10.1016/j.matchemphys.2016.03.022

\section{Published in:}

Materials Chemistry and Physics

\section{Citing this paper}

Please note that where the full-text provided on Manchester Research Explorer is the Author Accepted Manuscript or Proof version this may differ from the final Published version. If citing, it is advised that you check and use the publisher's definitive version.

\section{General rights}

Copyright and moral rights for the publications made accessible in the Research Explorer are retained by the authors and/or other copyright owners and it is a condition of accessing publications that users recognise and abide by the legal requirements associated with these rights.

\section{Takedown policy}

If you believe that this document breaches copyright please refer to the University of Manchester's Takedown Procedures [http://man.ac.uk/04Y6Bo] or contact uml.scholarlycommunications@manchester.ac.uk providing relevant details, so we can investigate your claim.

\section{OPEN ACCESS}




\title{
Characterization of a silica-PVA hybrid for high density and stable silver dissolution
}

\author{
Bryce Dorin ${ }^{\mathrm{a}, \mathrm{b}, *}$, Guangyu Zhuc, Patrick Parkinson ${ }^{\mathrm{a}, \mathrm{d}}$, Walter Perriec ${ }^{\mathrm{c}}$, Med Benyezzar ${ }^{\mathrm{a}}$, Patricia Scully, \\ ${ }^{a}$ The Photon Science Institute, The University of Manchester, Oxford Road, Manchester, UK, M13 9PL \\ ${ }^{b}$ School of Chemical Engineering and Analytical Science, The University of Manchester, Oxford Road, Manchester, UK, M13 9PL \\ ${ }^{c}$ Lairdside Laser Engineering Centre, The University of Liverpool, Campbeltown Road, Merseyside, UK, CH41 9HP \\ ${ }^{d}$ School of Physics and Astronomy, The University of Manchester, Oxford Road, Manchester, UK, M13 9PL
}

\begin{abstract}
A silica and polyvinyl alcohol (PVA) hybrid material mixed with a high density of silver ions is synthesised and characterized in this work. The hybrid material can be cast into thick films, which we determined to be homogeneous using Raman spectroscopy. We observed that the silver ions remain stable in the material over time and at temperatures of $100^{\circ} \mathrm{C}$, which represents a marked improvement over previous solid solutions of silver. Differential scanning calorimetry and thermogravimetric analysis indicate the rapid activation of silver at $173^{\circ} \mathrm{C}$, resulting in a dense formation of silver nanoparticles within the hybrid. The activation of silver was also demonstrated in 3-dimensional geometries using femtosecond duration laser pulses. These results illustrate the silica-PVA hybrid is an attractive material for developing silver-insulator composites.
\end{abstract}

Keywords:

composite materials, nanostructures, irradiation effects, optical properties

\section{Introduction}

A wide range of insulators exist that are capable of storing large amounts of metal ions. If the concentration of metal ions is below the saturation point of the host insulator, they can be dissolved without drastically changing the material's mechanical, optical, or electrical properties. These solid solutions form an interesting class of materials for creating metal-insulator composites. As the metal is dissolved in ionic form, designers have freedom to create unique metal structures embedded within the host solids. Often, these structures can be produced at the nano-scale. A key example of this is the production of embedded metal nanoparticles, where the host material is responsible for the reduction of the metal ions to atoms, and stabilization of the resulting nanoparticles. The surface plasmon resonance

\footnotetext{
${ }^{*}$ Corresponding author

Email addresses:

bryce.dorin@postgrad.manchester.ac.uk (Bryce Dorin), g.zhu@liverpool.ac.uk (Guangyu Zhu),

patrick.parkinson@manchester.ac.uk (Patrick Parkinson), wpfemto1@liverpool.ac.uk (Walter Perrie),

med.benyezzar@manchester.ac.uk (Med Benyezzar),

patricia.scully@manchester.ac.uk (Patricia Scully)
}

(SPR) of these encapsulated nanoparticles has been exploited for micro-polarizers [1], optical sensors [2], and 3D optical storage units [3]. Materials with embedded metal nanoparticles can also exhibit antimicrobial properties $[4,5]$. Conductive structures can be produced when high concentrations of metal ions are dissolved in the host material. These structures are often designed to function as electrical wires $[6,7,8]$, diodes [9], or switches $[10,11]$.

In most cases it is metals such as copper, [12, 13], gold $[14,15]$ and silver $[16,17]$ that are dissolved into insulating materials because of their high electrical conductivities. The host materials are often transparent dielectrics, which allow them to be used in optical applications. Common host materials include glasses $[18,19]$ and polymers $[20,21]$. To activate the ions dissolved in an insulator and form a metal-insulator composite, the ions must first be reduced to atoms. The reduction can be carried out through electrical processes, where a current directly reduces the ions [11]. Heating $[22,23]$ and laser irradiation with pulse lengths ranging from nanoseconds to femtoseconds $[24,25]$ can also activate the silver. These processes cause chemical and structural changes in the host insulator, which produce 
free electrons that reduce the metal ions.

Although many attempts have been made, researchers have yet to find an insulating and transparent host material that is ideal for fabricating silver-insulator composites. The most important characteristic of any metal ion host is a high saturation point (the ion concentration at which the host material's properties begin to change). Stability of the metal ions over time and at moderate temperatures is also important to ensure silver is not activated spontaneously, which would compromise the performance of the composite. For many applications, such as those that require laser processing within the bulk [26], thick and mechanically robust films are an additional requirement. One of the first materials used to dissolve silver was silica glass. Glass is an attractive host as it can stabilize dissolved silver for long periods of time and at temperatures up to $400^{\circ} \mathrm{C}$ [1]. Early attempts infused silver ions into the glass matrix through ion-exchange $[16,24]$, which produced low silver concentrations $(<1 \mathrm{wt} . \%)$ and very poor uniformity through the thickness of the glass. Ion concentrations were improved to $\sim 4 \mathrm{wt}$. $\%$ using high voltages to induce ionexchange, yet the ions were still confined to the surface of the sample [22]. Melt-quench techniques solved the problem of poor uniformity, and have demonstrated silver concentrations of $\sim 8 \mathrm{wt}$. $\%$ uniformly distributed in the glass [18]. However, fabricating these glasses requires very high processing temperatures, limiting the number of potential applications.

Solution processing is a convenient way to homogeneously combine insulators and silver ions in high densities. Salts such as silver nitrate are readily soluble in many solvents. In addition, casting materials from solution allows one to create films and coatings without high temperatures. The sol-gel process is a well studied method capable of synthesising silica from solution. This process has been exploited many times to uniformly dissolve silver in glass films, with concentrations as high as 8 wt.\% $[9,10,27]$. However, the solgel process is not suited to producing crack-free films thicker than $1 \mu \mathrm{m}$ [28]. Using solution processing, the production of silver-polymer composites also becomes relatively straightforward. Various polymers such as polyvinyl alcohol (PVA) [17, 23], polyvinyl pyrrolidone (PVP) [6, 20], polyethylene oxide (PEO) [11], and gelatin [21] have been used in the past as hosts for silver ions. Polymers can generally dissolve large quantities of silver, but they lack stability when compared to glass. Exposure to light and room temperatures can initiate the reduction of silver ions to solid metal in polymers, compromising the performance of the material. A limited number of glass/organic hybrids have been developed to dissolve silver ions $[29,30]$, yet these examples also lacked stability in ambient conditions.

Here we report the design and characterization of a novel silver ion solid solution for the production of silver-insulator composites. The insulating host must be capable of dissolving concentrations of silver ions that are comparable with the polymer and glass materials previously demonstrated [10]. The host also needs to stabilize the silver ions for long periods of time and at moderate temperatures by inhibiting their spontaneous reduction to silver metal. Finally, it needs to be mechanically robust to form thick, free-standing films. To reach these goals a hybrid of sol-gel glass and polymer was formulated. The sol-gel precursor molecule used is tetraethyl orthosilicate (TEOS), and the polymer constituent is PVA. The improved stability of the novel hybrid is demonstrated over time and at moderate temperatures using PVA samples as a reference. Silver structures were then formed in the hybrid using high temperatures and femtosecond laser irradiation as activation mechanisms, demonstrating the material is a viable starting point for silver-insulator composites.

\section{Experimental details}

\subsection{Sample preparation}

TEOS, silver nitrate, and PVA (130000 g/mol) were all purchased from Sigma-Aldrich and used without further purification. The silica sol-gel solution was prepared first. The reactants were mixed in volume ratios of 3:3:1 for TEOS:ethanol: $\mathrm{HNO}_{3}(0.2 \mathrm{M})$, respectively [27]. The dilute acid was added to act as a source of $\mathrm{H}_{2} \mathrm{O}$ to initiate hydrolysis, and to adjust the $\mathrm{pH}$ of the solution to 2 for a more interconnected gel [31]. The ethanol acted as a solvent for the solution. The gelling process was allowed to continue until a viscous gel was achieved, which took 1-2 days. Silver nitrate was then added to the solution and dissolved. Following this, a PVA solution with a weight ratio of 10:1 for $\mathrm{H}_{2} \mathrm{O}$ :PVA was mixed with the sol-gel. The final weight ratio for the different phases in the solution was 1:1:0.18 for $\mathrm{SiO}_{2}: \mathrm{PVA}: \mathrm{Ag}^{+}$.

Hybrid samples were prepared by solution casting the mixture into polystyrene dishes. The solution was dried slowly at room temperature to cast films up to $3 \mathrm{~mm}$ thick, which were peeled from the dishes. Reference samples containing only PVA and silver nitrate were also cast. The weight ratio for these samples was 1:0.18 for PVA: $\mathrm{Ag}^{+}$. Hybrid films without silver nitrate were used as a second set of reference samples, with 
the weight ratio 1:1 for $\mathrm{SiO}_{2}$ :PVA. No silica-silver reference samples were used as crack-free films could not be prepared without the addition of PVA.

\subsection{Characterization}

A Renishaw 1000 Micro-Raman system with a $514 \mathrm{~nm}$ pump laser was used to determine the structure of the hybrid films. The beam was focused using a 50x objective to a spot size $<1 \mu \mathrm{m}$.

The presence of silver nanoparticles in the films was assessed using UV-Vis-NIR absorption spectroscopy. This method can identify silver nanoparticle SPR absorption peaks in the $400-450 \mathrm{~nm}$ wavelength range. The detection of these peaks is strong evidence that solid silver has formed in the sample $[32,33]$. In some cases X-ray diffraction (XRD) was also used to confirm the presence of solid silver on a Bruker D8Advance diffractometer.

Thermogravimetric analysis (TGA) and differential scanning calorimetry (DSC) were performed simultaneously on a Mettler Toledo TGA/DSC1. The measurements were carried out in a flowing $\mathrm{N}_{2}$ atmosphere at $100 \mathrm{ml} / \mathrm{min}$ and $1 \mathrm{~atm}$. The scan operated from $30^{\circ} \mathrm{C}$ to $1000^{\circ} \mathrm{C}$ at a constant heating rate of $10^{\circ} \mathrm{C} / \mathrm{min}$.

\subsection{Laser irradiation}

A schematic of the laser irradiation set-up is presented in Fig. 1. The femtosecond laser source is a Clark-MXR CPA 2010, which delivered $170 \mathrm{fs}$ pulses at $1 \mathrm{kHz}$ and a center wavelength of $775 \mathrm{~nm}$. The energy per pulse was adjusted using a diffractive attenuator. These pulses were then frequency doubled using a beta-barium borate (BBO) crystal to $387.5 \mathrm{~nm}$. A shutter was used to block the beam between scans. Two lenses with numerical apertures (NAs) of 0.1 and 0.45 were used to focus the beam down to 7 and $2 \mu \mathrm{m}$ spot sizes, respectively. The pulse energy exiting the lens was measured with a pyro-electric detector (Coherent J5-09). The focus of the laser was positioned within the bulk of the sample for material processing. An Aerotech $\mathrm{X}-\mathrm{Y}-\mathrm{Z}$ stage raster scanned the sample along the focal plane of the beam at a speed of $0.5 \mathrm{~mm} / \mathrm{s}$ with a pitch of $20 \mu \mathrm{m}$ (unless otherwise stated) to create a large processed area. Absorption spectroscopy was used following the irradiation to analyse the processed area.

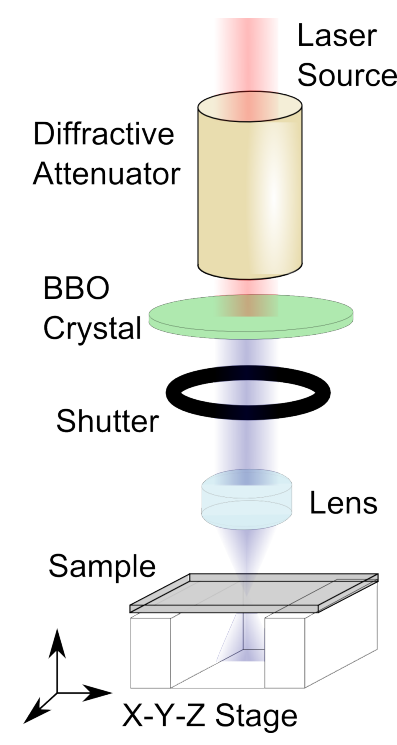

Figure 1: The optical pathway for femtosecond laser irradiation of the samples.

\section{Results and discussion}

\subsection{Raman spectroscopy}

The homogeneity of the silica-PVA hybrid films (without silver nitrate) was assessed using Raman spectroscopy. Five spectra were taken from different locations on a sample, which are presented in Fig. 2. The measured Raman spectra were found to be a superposition of the peaks associated with the chemical bonds in both silica and PVA. Measurements made at different locations fluctuate within the expected noise of the instrument, indicating that the PVA and silica phases remain uniformly distributed in the hybrid material after drying. Previous work indicates that the structure of the hybrid material consists of a PVA phase within a silica network $[31,34]$. We can therefore conclude that the separate phases must be $<1 \mu \mathrm{m}$ in size, or there would be noticeable fluctuations in the intensity of the Raman peaks between measurement locations.

\subsection{Time and temperature stability}

If the silver dissolved in PVA and silica remains in ionic form, both materials will maintain optical transparency. However, structural and chemical changes occurring over time or at elevated temperatures may lead to destabilization of the silver ions, resulting in the formation of nanoparticles. To assess the stability of silver ions in the hybrid material a variety of thermal and ageing treatments were applied to both hybrid and pure PVA samples containing silver, which are summarised 


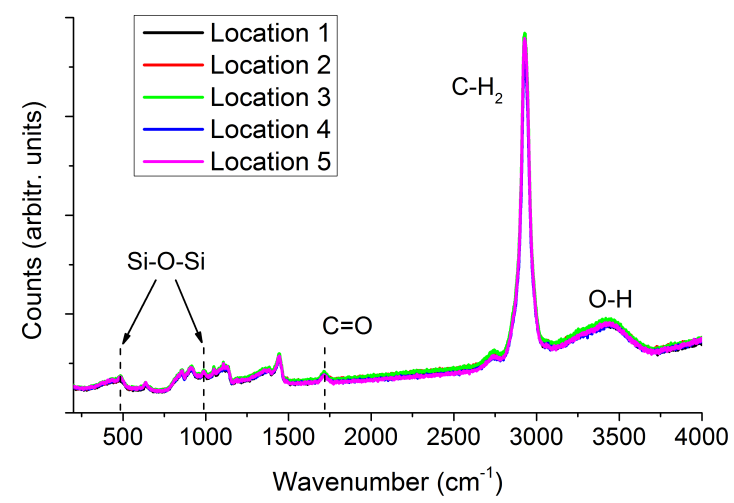

Figure 2: Raman spectroscopy of the PVA-silica hybrid material. Five spectra were taken from locations separated by $\sim 5 \mathrm{~mm}$ on a single sample. Some peaks have been labelled with their corresponding chemical bond [35, 36, 37, 38].

in Tab. 1. The thickness of the samples was $100 \mu \mathrm{m}$. The absorption spectra for each sample is provided in Fig. 3.

Table 1: Heat and ageing treatments applied to the PVA and hybrid samples.

\begin{tabular}{|c|c|}
\hline Label & Treatment \\
\hline PVA & PVA 1 day after casting \\
\hline PVA- $100^{\circ} \mathrm{C}$ & PVA after 1 hour at $100^{\circ} \mathrm{C}$ \\
\hline PVA-A & PVA 30 days after casting \\
\hline Hybrid & Hybrid 1 day after casting \\
\hline Hybrid- $100^{\circ} \mathrm{C}$ & Hybrid after 1 hour at $100^{\circ} \mathrm{C}$ \\
\hline Hybrid $-200^{\circ} \mathrm{C}$ & Hybrid after 1 minute at $200^{\circ} \mathrm{C}$ \\
\hline Hybrid-A & Hybrid 30 days after casting \\
\hline
\end{tabular}

The SPR absorption peaks centred at $\sim 410 \mathrm{~nm}$ in Fig. 3 indicate that silver nanoparticles are present in all PVA samples. Although the solution of PVA and silver nitrate was initially transparent, a small SPR peak formed after drying the film at room temperature for 1 day. This peak grew significantly both over time and after heating the film to $100^{\circ} \mathrm{C}$. The color of the films ranged from pale yellow (PVA) to deep amber (PVA$100^{\circ} \mathrm{C}$ and PVA-A). These results illustrate that the PVA host is intrinsically reducing the silver ions to metal [2].

The hybrid films did not show any evidence of solid silver forming over time or at temperatures up to $100^{\circ} \mathrm{C}$. This improved stability is likely a result of the $\mathrm{Ag}^{+}$ ions bonding with the non-bridging oxygen atoms in the silica, increasing the energy barrier required to reduce them [39]. However, at $200^{\circ} \mathrm{C}$ a rapid darkening of the film was observed that is attributed to the formation of silver nanoparticles. The high absorption of

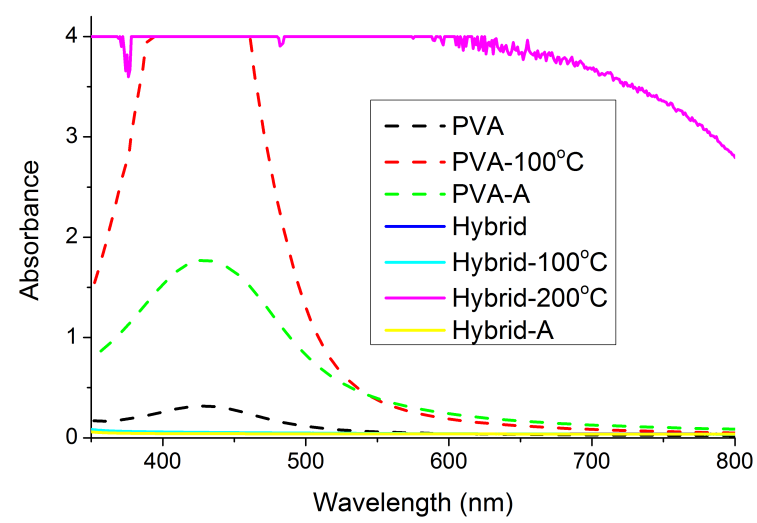

Figure 3: Absorption spectra for $100 \mu \mathrm{m}$ thick PVA and hybrid films after the treatments summarized in Tab. 1. The instrument exhibited saturation at an absorbance of 4 .

the film over the visible wavelength range suggests very high concentrations of nanoparticles, leading to aggregates [40]. To the eye the films appeared black, similar to photographic film. As no clear SPR absorption peak could be identified, XRD was used to verify the presence of silver nanoparticles in the hybrid $-200^{\circ} \mathrm{C}$ sample. The XRD spectra for the hybrid and hybrid $-200^{\circ} \mathrm{C}$ samples are displayed in Fig. 4. The peaks that emerge after the heat treatment correspond with the silver crystal planes, confirming that measurable densities of silver nanoparticles have formed.

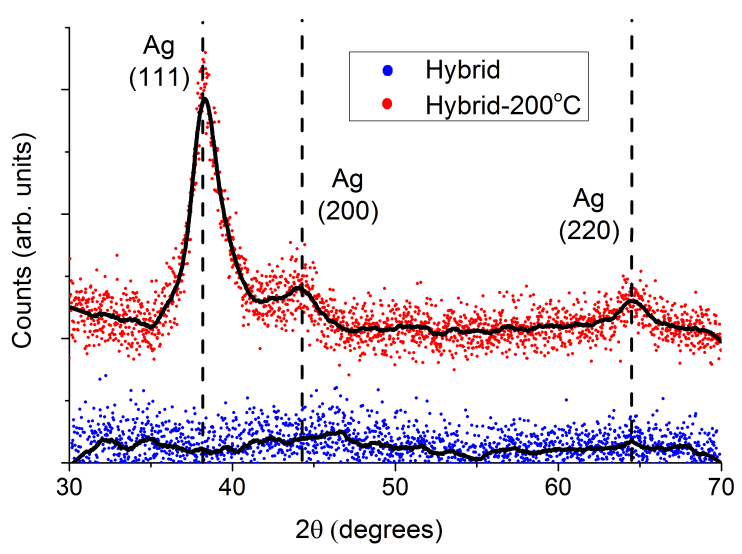

Figure 4: XRD spectra that confirms the presence of silver in the hybrid $-200^{\circ} \mathrm{C}$ film. The spectrum of an untreated hybrid film is included as a reference. The peak locations for each crystal plane of silver from the Bruker database are labelled using dashed lines. Smoothed data is shown for each sample using solid lines. 


\subsection{Thermal analysis}

To better characterize the thermal activation of silver in the hybrid material, TGA and DSC measurements were carried out on fresh samples with and without silver nitrate. Data from the measurements is presented in Fig. 5. As the temperature of samples is increased the weight loss is measured by the TGA, while the DSC measures the heat flow into the samples.

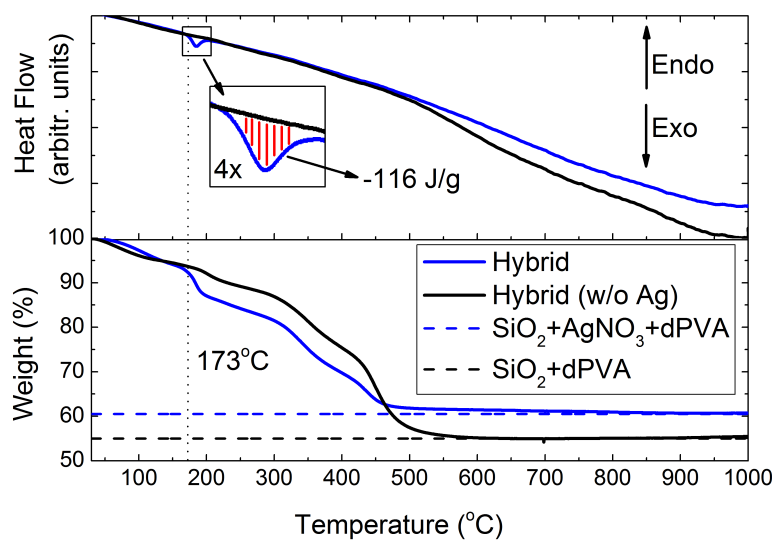

Figure 5: Thermal analysis of hybrid samples with and without silver nitrate. Bottom: TGA measurements. Top: DSC measurements. The volume of the dip in the hybrid DSC data (hatched in red) was integrated to determine the enthalpy of the reaction is $-116 \mathrm{~J} / \mathrm{g}$. The dashed lines indicate the predicted weights remaining after decomposition of the samples, where the decomposition products of PVA (labelled as dPVA) are equal to $10 \%$ of the original mass of PVA.

The TGA data in Fig. 5 shows four metastable regions separated by 3 sections of rapid decomposition in each sample. These trends match what has been observed in pure PVA [41]. The maximum temperature of $1000^{\circ} \mathrm{C}$ is well below the melting point of silica, therefore we do not expect any weight loss is due to decomposition of this phase. We conclude that the weight loss in the sample without silver nitrate is solely due to decomposition of the PVA phase to $10 \%$ of the original mass of PVA. The decomposition products of PVA have been labelled as dPVA in Fig. 5. It was found that for the hybrid sample containing silver nitrate, the weight of silica, dPVA and silver nitrate summed to the final weight of the sample after decomposition, indicating silver nitrate does not contribute to weight loss in the sample.

A dip at $173^{\circ} \mathrm{C}$ is notable in the DSC data from the hybrid sample with silver, which indicates an exothermic reaction has taken place. The location of this dip corresponds with the location of the first rapid decomposition in the sample. It is also at approximately this temperature that we observed nanoparticles forming in the hybrid in Fig. 3. Therefore, it is likely that these pro- cesses are linked. We propose that the process begins with the decomposition and chain splitting of PVA, generating free electrons [41]. These free electrons react with the silver ions, producing silver atoms which form nanoparticles. The enthalpy of the reaction is $-116 \mathrm{~J} / \mathrm{g}$, which was found by integrating the volume of the dip. Theoretically, the reduction of silver in the sample accounts for an enthalpy of $-77 \mathrm{~J} / \mathrm{g}$ [42]. The source of the remaining measured enthalpy may be other reactions occurring in the material, experimental error, or the temperature dependence of the enthalpy values in [42].

\subsection{Laser processing}

In addition to heating, femtosecond laser irradiation is a second method capable of facilitating the conversion of silver ions to atoms in the hybrid. Large areas of a $3 \mathrm{~mm}$ thick sample were irradiated with different pulse energies using a $0.1 \mathrm{NA}$ lens. The formation of nanoparticles was measurable immediately following the laser processing. For each pulse energy the absorbance of the irradiated area was measured. These results are presented in Fig. 6. The silver nanoparticle SPR peak grows as the pulse energy is increased, confirming that more silver atoms are produced with higher laser intensities. A small shoulder is apparent in the $2.0 \mu \mathrm{J}$ absorption spectrum, indicating that silver nanoparticle agglomerates form at this pulse energy [43]. The measured SPR peaks were found to agree well with the extinction spectra predicted by Mie's SPR theory [32]. The absorbance of a $36 \mathrm{~nm}$ diameter silver particle calculated using Mie's theory is plotted in Fig. 6 to illustrate the correlation with the $0.26 \mu \mathrm{J}$ experimental data.

It is evident in Fig. 3 that the hybrid material is transparent to the $387.5 \mathrm{~nm}$ light of the laser. The band gap of the hybrid material $\left(E_{B}\right)$ was found to be $4.7 \mathrm{eV}$ through absorption spectroscopy, greater than the laser's photon energy $\left(E_{P}\right)$ of $3.2 \mathrm{eV}$. Therefore, $E_{P}<E_{B}<2 E_{P}$, indicating that a two-photon effect is responsible for absorption of the radiation in the high intensity focal region. Since absorption only occurs at the beam focus, silver nanoparticles can be formed selectively throughout the thickness of the sample. This 3-dimensional processing capability is clear in the cross-sectional image in Fig. 7 , where several points have been irradiated at different focal depths using a $0.45 \mathrm{NA}$ objective and a $0.49 \mu \mathrm{J}$ pulse energy. It is apparent that the measured length of material modification in Fig. $6(\sim 50 \mu \mathrm{m})$ is much greater than the depth of focus of the beam, calculated to be $1.4 \mu \mathrm{m}$. This observation indicates that filamentation due to a balance between self-focusing and plasma 


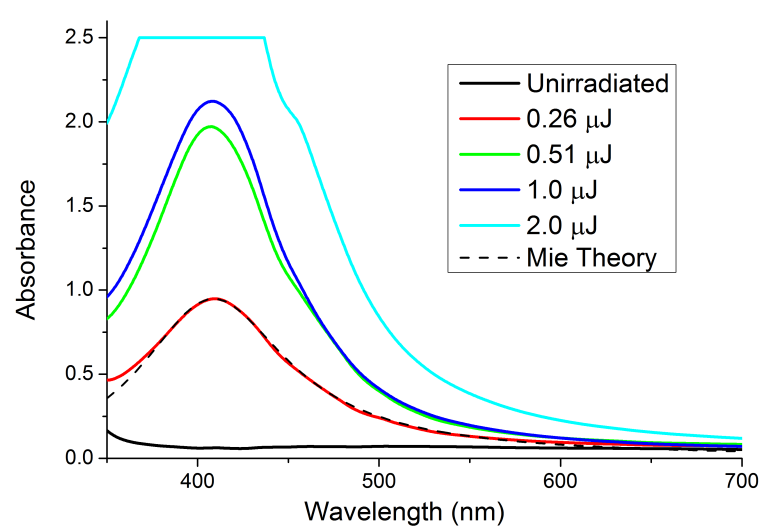

Figure 6: The absorption spectra of a $3 \mathrm{~mm}$ thick hybrid sample after femtosecond laser irradiation using various pulse energies and a $0.1 \mathrm{NA}$ lens. Mie's SPR theory shows excellent agreement with the $0.26 \mu \mathrm{J}$ spectrum. The instrument exhibited saturation at an absorbance of 2.5 .

de-focusing has occurred in the filamentary region [44]. The regions of two-photon absorption are distinguished by the yellow/amber color of the silver nanoparticles formed. The darker amber color in the focal region indicates a higher concentration of nanoparticles form in the vicinity of filamentation. The reduction of silver in these samples is purely a photochemical process as the average laser power is low enough to eliminate any thermal effects. Both PVA and silica have demonstrated the photoreduction of silver through femtosecond laser irradiation in previous studies $[17,24]$, therefore it is likely that each material contributes to the process in the hybrid.

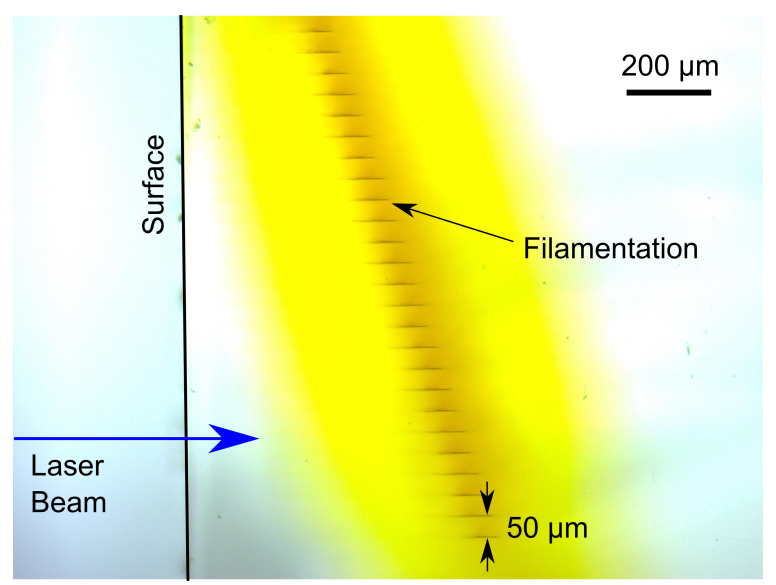

Figure 7: A cross-sectional unprocessed bright-field image demonstrating laser processing within the bulk of a $3 \mathrm{~mm}$ thick hybrid sample. The pulse energy was $0.49 \mu \mathrm{J}$ focused using a 0.45 NA lens. The focal position is shifted into the bulk of the sample in $10 \mu \mathrm{m}$ increments to demonstrate control over the processing area in 3dimensions. The area of the nanoparticle layer in the image is exaggerated slightly during imaging by the thickness of the sample $(\sim 1 \mathrm{~mm})$.

\section{Conclusions}

The results of this study illustrate the numerous advantages to a hybrid of PVA and silica when creating silver-insulator composites. The addition of PVA drastically improved the mechanical properties of the sol-gel silica. Samples with thicknesses of several millimetres were successfully cast without cracking, which is 3 orders of magnitude greater than what can be achieved with pure silica sol-gels. The decomposition of PVA at $173^{\circ} \mathrm{C}$ likely catalyses the reduction of silver in the hybrid, resulting in a dense matrix of silver nanoparticles. The addition of silica to the hybrid resulted in a considerable improvement in silver ion stability when compared to PVA-AgNO ${ }_{3}$ samples. Ageing for a month and temperatures of $100^{\circ} \mathrm{C}$ did not lead to any measurable quantities of silver nanoparticles forming. In contrast, the PVA-AgNO $\mathrm{An}_{3}$ samples exhibited large SPR absorption peaks characteristic of silver nanoparticles after the same treatments. The marked improvement in mechanical characteristics and silver stability, as well as the high silver density, make this hybrid material attractive for the fabrication of silver-insulator composites. We have demonstrated the controlled precipitation of silver nanoparticles in 3-dimensions using femtosecond laser irradiation. These results point towards industrially viable 3-dimensional metal structures embedded within insulating materials. 


\section{Acknowledgements}

The authors would like to thank John Waters for his assistance with the XRD measurements, and Martin Jennings for performing the DSC and TGA measurements. Research funding was provided through the President's Doctoral Scholarship awarded to Bryce Dorin from The University of Manchester.

\section{References}

[1] A. Stalmashonak, G. Seifert, A. A. Unal, U. Skrzypczak, A. Podlipensky, A. Abdolvand, H. Graener, Toward the production of micropolarizers by irradiation of composite glasses with silver nanoparticles, Applied optics 48(25) (2009) F38-F44.

[2] A. Nimrodh Ananth, S. Umapathy, J. Sophia, T. Mathavan, D. Mangalaraj, On the optical and thermal properties of in situ/ex situ reduced Ag NPs/PVA composites and its role as a simple SPR-based protein sensor, Applied Nanoscience 1(2) (2011) 87-96. doi:10.1007/s13204-011-0010-7.

[3] A. Stalmashonak, A. Abdolvand, G. Seifert, Metal-glass nanocomposite for optical storage of information, Applied Physics Letters 99(20) (2011) 201904. doi:10.1063/1.3660740.

[4] H. Kong, J. Jang, Antibacterial Properties of Novel Poly (methyl methacrylate) Nanofiber Containing Silver Nanoparticles, Langmuir 24 (2008) 2051-2056.

[5] S. Jaiswal, P. McHale, B. Duffy, Preparation and rapid analysis of antibacterial silver, copper and zinc doped sol-gel surfaces, Colloids and Surfaces B: Biointerfaces 94 (2012) 170176. doi:10.1016/j.colsurfb.2012.01.035.

[6] R. Nakamura, K. Kinashi, W. Sakai, N. Tsutsumi, Fabrication of the silver structure through two-photon excitation by femtosecond laser, Chemical Physics Letters 610-611 (2014) 241-245. doi:10.1016/j.cplett.2014.07.044.

[7] S. Maruo, T. Saeki, Femtosecond laser direct writing of metallic microstructures by photoreduction of silver nitrate in a polymer matrix, Optics Express 16(2) (2008) 1174-1179. doi:10.1364/OE.16.001174.

[8] C. N. Lafratta, D. Lim, K. O. Malley, T. Baldacchini, J. T. Fourkas, Direct Laser Patterning of Conductive Wires on ThreeDimensional Polymeric Microstructures, Chemistry of Materials 23(5) (2006) 2038-2042.

[9] A. Dan, B. Satpati, P. V. Satyam, D. Chakravorty, Diodelike behavior in glass-metal nanocomposites, Journal of Applied Physics 93(8) (2003) 4794-4800. doi:10.1063/1.1559429.

[10] D. K. Sarkar, F. Cloutier, M. A. E. Khakani, Electrical switching in sol-gel derived Ag-SiO2 nanocomposite thin films, Journal of Applied Physics 97 (2005) 084302. doi:10.1063/1.1870112.

[11] S. Wu, T. Tsuruoka, K. Terabe, T. Hasegawa, J. P. Hill, K. Ariga, M. Aono, A polymer-electrolyte-based atomic switch, Advanced Functional Materials 21 (2011) 93-99. doi:10.1002/adfm.201001520.

[12] J. M. P. Almeida, L. De Boni, W. Avansi, C. Ribeiro, E. Longo, A. C. Hernandes, C. R. Mendonca, Generation of copper nanoparticles induced by fs-laser irradiation in borosilicate glass, Optics express 20(14) (2012) 15106-15113.

[13] J. Rozra, I. Saini, A. Sharma, N. Chandak, S. Aggarwal, R. Dhiman, P. K. Sharma, $\mathrm{Cu}$ nanoparticles induced structural, optical and electrical modification in PVA, Materials Chemistry and Physics 134 (2012) 1121-1126. doi:10.1016/j.matchemphys.2012.04.004.
[14] H. El Hamzaoui, R. Bernard, A. Chahadih, F. Chassagneux, L. Bois, B. Capoen, M. Bouazaoui, Continuous laser irradiation under ambient conditions: A simple way for the space-selective growth of gold nanoparticles inside a silica monolith, Materials Research Bulletin 46 (2011) 1530-1533. doi:10.1016/j.materresbull.2011.05.010.

[15] M. K. Abyaneh, R. Pasricha, S. W. Gosavi, S. K. Kulkarni, Thermally assisted semiconductor-like to insulator transition in gold-poly(methyl methacrylate) nanocomposites, Nanotechnology 17 (2006) 4129-4134. doi:10.1088/0957-4484/17/16/023.

[16] K. J. Berg, A. Berger, H. Hofmeister, Small silver particles in glass surface layers produced by sodium-silver ion exchange - their concentration and size depth profile, $\mathrm{Z}$. Phys. D - Atoms, Molecules and Clusters 20 (1991) 309-311. doi:10.1007/BF01543998.

[17] R. Kuladeep, L. Jyothi, S. Chakradhar, D. Narayana Rao, Fabrication of metal nanostructures in a polymer matrix using femtosecond laser writing technique, Optical Engineering 53(7) (2014) 071823. doi:10.1117/1.OE.53.7.071823.

[18] M. Bellec, A. Royon, B. Bousquet, K. Bourhis, M. Treguer, T. Cardinal, M. Richardson, L. Canioni, Beat the diffraction limit in 3D direct laser writing in photosensitive glass, Optics express 17(12) (2009) 10304-10318.

[19] Y. Dai, G. Yu, M. He, H. Ma, X. Yan, G. Ma, High repetition rate femtosecond laser irradiation-induced elements redistribution in Ag-doped glass, Applied Physics B 103(3) (2010) 663667. doi:10.1007/s00340-010-4330-1.

[20] T. Baldacchini, A.-C. Pons, J. Pons, C. Lafratta, J. Fourkas, Y. Sun, M. Naughton, Multiphoton laser direct writing of two-dimensional silver structures, Optics express 13(4) (2005) 1275-80.

[21] S. Kang, K. Vora, E. Mazur, One-step direct-laser metal writing of sub-100 nm 3D silver nanostructures in a gelatin matrix, Nanotechnology 26(12) (2015) 121001. doi:10.1088/09574484/26/12/121001.

[22] S. Wackerow, G. Seifert, A. Abdolvand, Homogenous silverdoped nanocomposite glass, Optical Materials Express 1(7) (2011) 1224-1231. doi:10.1364/OME.1.001224.

[23] S. Porel, S. Singh, S. S. Harsha, D. N. Rao, T. P. Radhakrishnan, Nanoparticle-Embedded Polymer: In Situ Synthesis, FreeStanding Films with Highly Monodisperse Silver Nanoparticles and Optical Limiting, Chemistry of Materials 17(1) (2005) 912. doi: $10.1021 / \mathrm{cm} 0485963$

[24] J. Qiu, M. Shirai, T. Nakaya, J. Si, X. Jiang, C. Zhu, K. Hirao, Space-selective precipitation of metal nanoparticles inside glasses, Applied Physics Letters 81(16) (2002) 3040-3042. doi:10.1063/1.1509095.

[25] S. Wackerow, A. Abdolvand, Generation of silver nanoparticles with controlled size and spatial distribution by pulsed laser irradiation of silver ion-doped glass., Optics express 22(5) (2014) 5076-5085. doi:10.1364/OE.22.005076.

[26] G. Seifert, A. Podlipensky, A. Abdolvand, H. Graener, Production of dichroitic 3D structures by fs laser irradiation in composite glass containing Ag nanoparticles, Photon Processing in Microelectronics and Photonics V 6106 (2006) 61061Q. doi:10.1117/12.646412.

[27] A. Babapour, O. Akhavan, R. Azimirad, A. Z. Moshfegh, Physical characteristics of heat-treated nano-silvers dispersed in sol-gel silica matrix, Nanotechnology 17 (2006) 763-771. doi:10.1088/0957-4484/17/3/025.

[28] P. Innocenzi, M. O. Abdirashid, M. Guglielmi, Structure and Properties of Sol-Gel Coatings from Methyltriethoxysilane and Tetraethoxysilane, Journal of Sol-Gel Science and Technology 3 (1994) 47-55. doi:10.1007/BF00490148.

[29] S. C. Warren, M. R. Perkins, A. M. Adams, M. Kamperman, 
A. A. Burns, H. Arora, E. Herz, T. Suteewong, H. Sai, Z. Li, J. Werner, J. Song, U. Werner-Zwanziger, J. W. Zwanziger, M. Grätzel, F. J. DiSalvo, U. Wiesner, A silica sol-gel design strategy for nanostructured metallic materials, Nature Materials 11(5) (2012) 460-467. doi:10.1038/nmat3274.

[30] T. Y. Chen, C. K. Chiu, Y. J. Choi, T. J. M. Luo, T. L. Lin, Formation of self-aggregated and interconnected silver network within sol-gel silica, Journal of Materials Science 48 (2013) 850-856. doi:10.1007/s10853-012-6806-3.

[31] C. Brinker, G. Scherer, Sol-Gel Science: The Physics and Chemistry of Sol-Gel Processing, 1990.

[32] A. Stalmashonak, G. Seifert, A. Abdolvand, Ultra-Short Pulsed Laser Engineered Metal-Glass Nanocomposites, SpringerBriefs in Physics, Springer International Publishing, Heidelberg, 2013. doi:10.1007/978-3-319-00437-2.

[33] S. Thomas, S. K. Nair, E. M. A. Jamal, S. H. Al-Harthi, M. R. Varma, M. R. Anantharaman, Size-dependent surface plasmon resonance in silver silica nanocomposites, Nanotechnology 19(7) (2008) 075710. doi:10.1088/0957-4484/19/7/075710.

[34] R. K. Nagarale, V. K. Shahi, R. Rangarajan, Preparation of polyvinyl alcohol-silica hybrid heterogeneous anionexchange membranes by sol-gel method and their characterization, Journal of Membrane Science 248 (2005) 37-44. doi:10.1016/j.memsci.2004.09.025.

[35] S. Hajatdoost, J. Yarwood, Depth Profiling of Poly(methyl methacrylate), Poly(vinyl alcohol) Laminates by Confocal Raman Microspectroscopy, Applied Spectroscopy 50(5) (1996) $558-564$.

[36] T. Kozai, S. Yamashita, K. Hirochi, H. Miyagawa, N. Tsurumachi, S. Koshiba, S. Nakanishi, H. Itoh, Molecular vibrational dynamics in polyvinyl alcohol studied by femtosecond coherent anti-stokes Raman spectroscopy, Chemical Physics Letters 553 (2012) 26-29. doi:10.1016/j.cplett.2012.09.057.

[37] H.-J. Jeon, S.-C. Yi, S.-G. Oh, Preparation and antibacterial effects of Ag-SiO2 thin films by sol-gel method, Biomaterials 24(27) (2003) 4921-4928. doi:10.1016/S0142-9612(03)004150 .

[38] D. P. Pham, K. K. Huynh, C. V. Tran, V. Q. Vu, T. T. V. Tran, Preparation and Structural Characterization of Sol-GelDerived Silver Silica Nanocomposite Powders, International Journal of Materials Science and Applications 3(5) (2014) 147151. doi:10.11648/j.ijmsa.20140305.13.

[39] R. Araujo, Colorless glasses containing ion-exchanged silver, Applied optics 31(25) (1992) 5221-5224. doi:10.1364/AO.31.005221.

[40] V. Markel, V. M. Shalaev, E. B. Stechel, W. Kim, R. L. Armstrong, Small-particle composites. I. Linear optical properties, Physical Review B 53(5) (1996) 2425-2436.

[41] J. W. Gilman, D. L. VanderHart, T. Kashiwagi, Thermal Decomposition Chemistry of Poly ( vinyl alcohol ), Fire and Polymers II Materials and Test for Hazard Prevention ACS 599 (1995) 161-185.

[42] R. G. Mortimer, Physical Chemistry 2nd ed., 2000.

[43] V. Amendola, O. M. Bakr, F. Stellacci, A study of the surface plasmon resonance of silver nanoparticles by the discrete dipole approximation method: Effect of shape, size, structure, and assembly, Plasmonics 5 (2010) 85-97. doi:10.1007/s11468-0099120-4.

[44] K. Yamada, W. Watanabe, K. Kintaka, J. Nishii, K. Itoh, Volume Grating Induced by a Self-Trapped Long Filament of Femtosecond Laser Pulses in Silica Glass, Japanese Journal of Applied Physics, 42 (2003) 6916-6919. doi:10.1143/JJAP.42.6916. 